\title{
Lean Six Sigma Approach to Improve the Production Process in the Mould Industry: a Case Study
}

DOI: 10.12776/QIP.V23I3.1334

\author{
António M.H. Pereira, Miguel R. Silva, Mercedes A.G. Domingues, \\ José C. Sá
}

Received: 01 November 2019 Accepted: 19 November 2019 Published: 30 November 2019

\begin{abstract}
Purpose: The purpose of this article is to explore the optimization of internal process is assumed as a critical factor to be capable of answering to the moulds industries. Consequently, it has been considered essential to adopt high-valued methodologies to support tooling industry in order to achieve global competitive advantages. For that purpose, this work aims to apply LEAN principles and techniques to support mould design and manufacturing processes.
\end{abstract}

Methodology/Approach: The methodology used was based on PDCA/DMAIC, with the following stages: Define, Measure, Analyze, Improve and Control. For each stages was taken some of Lean Six Sigma techniques, such as Continuous Improvement, Value Stream Mapping, Pareto analysis and Overall Equipment Effectiveness.

Findings: This study results was revealed that there are many areas on the organizations in the Mould Industry, when they utilize otimizations tools obtain hugt successes. With the Pareto analysis was carried out to show that events that contributes the most to the stops. The results were: unavailability of the operator $(16.4 \%)$, programming the machine $(14.4 \%)$ and tool exchange $(12.4 \%)$ In the case of this Mould Industry study was obtained for the CNC machines studies, with the implementation of Lean Six Sigma tools as obtained a improvement about $20 \%$ of global OEE.

Research Limitation/implication: This research was revealed that there the moulds are Project unique and difficult to analyze. Moreover, this paper reports that the approach LEAN Six Sigma is very interesting for the continuous improvement of processes and profitability of moulds industry.

Originality/Value of paper: This research highlight areas of future research using of quality management methods and Lean Six Sigma tools to analyse and 
optimize production in the moulds industry. Therefore this research It is considered to promote and adopt high-valued methodologies to support tooling industry in order to achieve global competitive advantages.

Category: Case study

Keywords: mould; Lean Six Sigma; VSM; Pareto diagram; OEE

\section{INTRODUCTION}

Most injection mould manufacturers in Portugal are generally characterized by their high technological standards, high engineering knowledge and high performance in terms of overall mould quality and customer service. However, the injection mould industry has faced several challenges posed by globalization (ISTMA World, 2007). This create a set of threats, promoting competitiveness, and compels companies to be more efficient, by seeking new opportunities for innovation and for market and also with the improvement and effectiveness on yours internal processes.

The production process of injection moulds has several difficulties to overtake namely the uniqueness of each mould, the simultaneous production of myriad components from several moulds and recurrent mould design changes asked by the customer (Jorge and Peças, 2018). However, these companies have a challenge to remain at the level of excellence by responding to an increasingly demanding market in terms of mould complexity, ever shorter delivery times and a continuing and growing environmental concern, together with waste minimization. The challenge listed above result in the need to reduce waste and time without added value, where maximizing the use of high technology resources is relevant and differentiating (WEF, 2016; Henriques and Peças, 2012; Wongwiwat, Bohez and Pisuchpen, 2013). This complexity manufacturing results in a very unstable and dynamic process flows and, as such, waste in the mould production chain is difficult to identify and assess. For overtake this difficulty this paper presents the results of a research aiming to understand the applicability of Lean tools to the mould making industry. The underlying principle at continuous improvement is it guided towards the efficiency of the global process (Jorge and Peças, 2018).

One objective of this study regarding the applicability of Lean tools to the mould industry is keep the information available and disseminated. If possible that information must be available in Knowledge database. The process of knowledge management results from the need to survive in a world dominated by innovation, and the need for its management is based on the creation of value (Santos et al., 2019). So, databases might be a solution to promote creation of value and scientific production (Figueiredo and Pereira, 2017).

Due to the increased competitiveness, the mould makers are under huge pressure in order to reduce their costs and provide products of higher quality in shorter 
lead times. This is possible if they improve their performance. Lean manufacturing can be used by manufacturing organizations to achieve these and obtain a competitive advantage over their rivals (Belekoukias, Garza-Reyes and Kumar, 2014; Garza-Reyes et al., 2012; Womack and Jones, 2003). This competitiveness is obtained by increasing efficiency and decreasing costs through the elimination of non-value added steps and inefficiencies in the production process (Sohal and Egglestone, 1994; Garza-Reyes et al., 2012). Lean was first introduced by Womack and Jones (1990) in their book "The Machine That Changed the World", which describes the Toyota production system (TPS) (Womack, Jones and Roos, 1990; Alaskari et al., 2012).

Nowadays, the optimization of internal process is assumed as a critical factor to be capable of answering to the high-tech industries, namely the automotive and aeronautics industries. Therefore all companies are confronted with constant changes in the markets for this the management processes that should be proactively applied (Araújo et al., 2019). Currently, the rapid change in global market imposes faster mould design and manufacturing in order to reduce the time-to-market, along with higher quality, greater efficiency and lower costs. Consequently, it has been considered essential to adopt high-valued methodologies to support tooling industry in order to achieve global competitive advantages. For that purpose, this work aims to apply Lean principles and techniques to support mould design and manufacturing processes. The injection mould is a high precision tool responsible for the production of most plastic parts used everywhere. Its main purpose is to replicate the desired geometry of the final plastic part by transforming molten plastic into its final shape and dimensional details. Thus, these tools are custom designed and built. Taken in to account these specific characteristics of moulds sector (Engineering \& Tooling), namely the design and manufacturing of unique and unrepeatable tools through a job shop production environment, significant adjustments were introduced in order to adapt some of traditional Lean techniques, such as Value Stream Mapping (VSM) and Overall Equipment Effectiveness (OEE), to this sector.

\section{LEAN MANUFACTURING}

Lean manufacturing is a management approach to make organizations more competitive by increasing efficiency and decreasing their costs and providing products of higher quality in shorter lead times e.g. promote the elimination of non-value added steps and inefficiencies in the process (Garza-Reyes et al., 2012). It is associated to the continuous improvement since that requires constant improvement of its practices (Marodin and Saurin, 2013). The major challenge to industry applying lean manufacturing is to implement a culture that will create and sustain long-standing commitment in the organization (Prakash and Sunil Kumar, 2011). To maintain the culture of continuous improvement we can used de PDCA cycle or a Kaizen what is methodology for a systematic approach that 
focuses on customer needs, oriented to the process and encourages the participation and proactivity of all collaborates (Glover et al., 2011).

As Ohno (1988) refers, the products delivery between the supplier and the costumer's order should be studied, and the wastes identified should be eliminated in order to reduce deadline of delivery. The original seven common wastes in an industrial environment that were identified (Ohno, 1988) are:

- Defects;

- Inventory;

- Motion;

- Over processing;

- Over production;

- Transportation;

- Waiting periods.

The Human talent is an additional waste more recently been pointed out as important and, should therefore, has been considered in the list (Liker and Meier, 2006). So, in addition to this, other types of waste can still be identified, namely; Waste of materials, Energy and Water; Pollution and Time.

The authors Womack and Jones (1996) referred Lean thinking as the "way to specify value, line up value creating actions in the best sequence, conduct these activities without interruption whenever someone requests them, and perform them more and more effectively". Five Lean principles were introduced to address the various challenges that occur within and between business units from the differences in business culture and management thought process. The Lean principles (Womack and Jones, 1996) are:

1. Define value from the customer;

2. Identify the value stream mapping;

3. Establish a continuous flow;

4. Implement pull system production;

5. Continuously search for perfection.

These principles (Fig. 1) have the goal to establish a perfect value stream by continuously identifying, and eliminating activities considered waste and focus on activities that create value. 


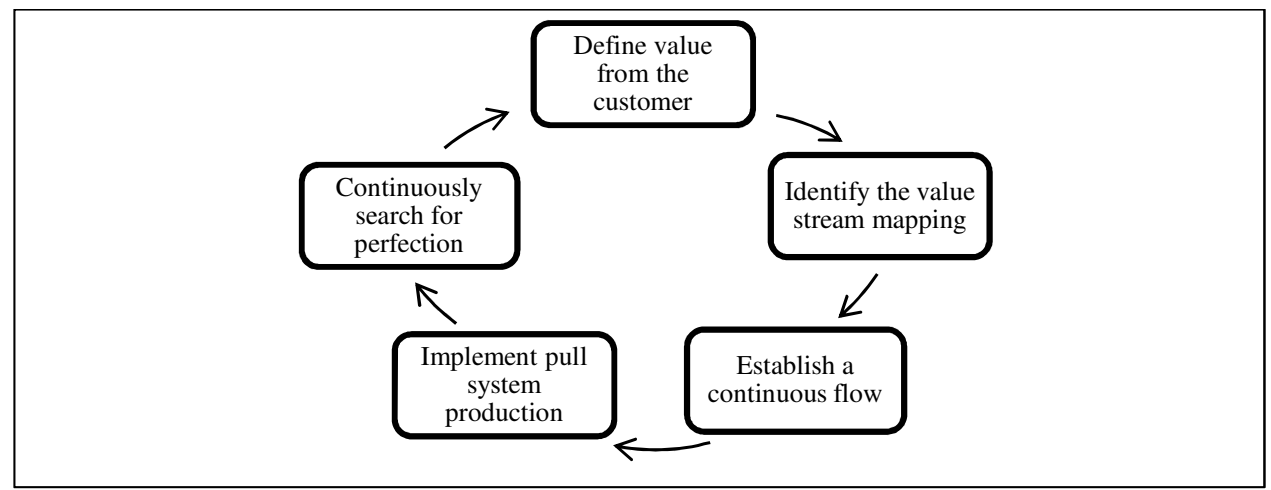

Figure 1-Lean Principles

Lean Manufacturing is a concept used in production systems through continuous improvement, elimination of waste and non-value-added operations by using a series tools and techniques (Manzouri et al., 2014; Thangarajoo and Smith, 2015). Lean was first introduced by Womack, Jones and Roos (1990) in their book "The Machine That Changed the World", which describes the Toyota production system (TPS). Womack and Jones (2003) describes Lean as: "The most powerful tool available for creating value while eliminating waste in any organization".

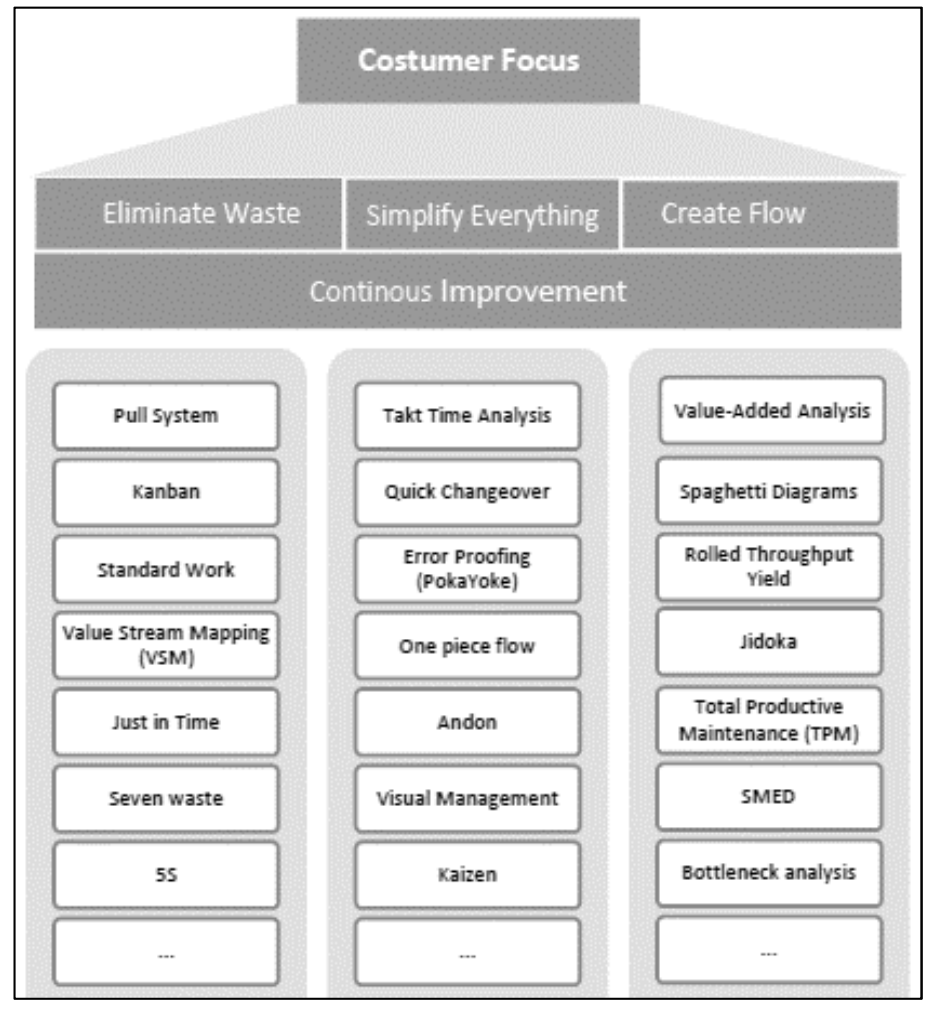

Figure 2 - Lean Tools 
The fundamental principles of Lean are visualization and "go and see" (Liker, 2004). These principles have been leading in the development of tools and techniques to achieve the target of continuous improvement (Fig. 2). There are many Lean techniques and tools design for waste reduction which can be applied to promote efficient material flows, shorten lead-time, and minimal waste of time (Araújo et al., 2019; Rother and Shook, 2003; Rother, 2010).

The mainly tools used in this research to obtain waste were: Kaizen/Continuous Improvement, Seven Basic Tools of Quality, 5S Methodology, Value Stream Mapping (VSM), and Overall Equipment Effectiveness (OEE).

\subsection{Kaizen/Continuous Improvement}

This signifies improving continuously in a short space of time or at low cost, supported by a team brought together to achieve goals. This tool have the same base of PDCA cycle, the quality management (Defeo and Juran, 2016). Kaizen is based on the principle that everything can be improved. Kaizen cycle for continuous improvement have seven steps that should be repeated on an ongoing basis, with new solutions, when appropriate, or with new problems. This seven steps are:

1. Get employees involved;

2. Find problems and potential opportunities;

3. Request creative solutions;

4. Test the solution;

5. Analyze the results;

6. Standardize;

7. Repeat these steps.

\subsection{Seven Basic Tools of Quality}

The Seven Quality Tools are simple statistical tools used for solving quality problems e.g. are used to find out root causes and eliminates them, thus the manufacturing process can be improved. These tools were either developed by the Quality Gurus such as Deming, Ishikawa and Juran. These are the most useful and simple to use. Kaoru has stated "that these seven tools can be used to solve 95 percent of all problems". The Seven Quality Tools used are; Check Sheets/Check List; Pareto Diagram; Ishikawa (Cause \& Effect) Diagram; Histogram; Control Charts; Scatter Diagrams and Graphs (Ishikawa, 1986; (Ishikawa, 1991; Magar and Shinde, 2014). 


\subsection{S Methodology}

The $5 \mathrm{~S}$ is a systematic technique used by organizations for workplace organization promoting its efficiency and decreasing the waste and consequently increasing the quality and productivity through an organized environment (Ghodrati and Zulkifli, 2013). The 5S methodology has 5 phases which use five Japanese words:

1. Seiri/Sort (organize);

2. Seiton/Set in order (create order);

3. Seiso/Shine (cleanliness);

4. Seiketsu/Standardize (standardized cleaning);

5. Shitsuke/Sustain (discipline).

It is known that $5 \mathrm{~S}$ techniques support the Organization's objectives to achieve continuous improvement and higher performance and, consequently, promotes a positive impact on organizational performance.

\subsection{Value Stream Mapping (VSM)}

VSM it allows the visual representation of all company processes, making the process analysis simple and intuitive, from the client request till the final delivery of products. VSM is a powerful tool to support continuous improvement and to decide and design improvement overall effectiveness of the process. The VSM has with objectives (Costa et al., 2012) the follows:

1. Make the current process visible;

2. Facilitate the identification of problems and opportunities for improvement;

3. Establish a reference for evaluating impacts of improvement actions;

4. Establish a working basis for the creation of an improved state of the process.

According to Hines and Rich (1997) associated it to seven waste are the seven value stream mapping tools, as indicated below:

1. Process activity mapping Industrial engineering;

2. Supply chain response matrix Time compression/logistics;

3. Production variety funnel Operations management;

4. Quality filter mapping New tool;

5. Demand amplification mapping Systems dynamics;

6. Decision point analysis Efficient consumer response/logistics;

7. Physical structure mapping. 


\subsection{Overall Equipment Effectiveness (OEE)}

Overall Equipment Effectiveness (OEE) is a Key Performance Indicators (KPIs) and a metric for evaluating the progress of Total Productive Maintenance (TPM). This is obtained with cumulative measure of three separate factors: availability, performance and quality. Together they can provide, with a good measure, of how well your plant is producing (Ayatollahi et al., 2013; Dutta and Dutta, 2016; 2017; Puvanasvaran, Teoh and Tay, 2013). OEE can be improved through analysis of the six big losses, and according to Tajiri and Gotoh (1992) the relationship between OEE and losses depends on equipment availability, their performance rates and the quality of the product. These authors classified major losses into six groups, where the breakdown losses, setup and adjustment losses are downtime losses and contribute to determine a true value for the availability of a machine. The losses including minor stoppage and reduced speed losses and are known as speed losses. They are contribute to measure of performance rate of a given machine. Finally, rework and yield losses are defined as quality losses to determine the quality rate for the equipment.

In summary, it can be considered that: the availability factor measures the total time that the system is not operating; the performance rate measures the ratio of the actual operating speed of the equipment as compared to its ideal speed and the quality factor measures the proportion of defective production to the total production volume (Jonsson and Lesshammar, 1999).

\section{METHODOLOGY/EXPERIMENTAL PROCEDURE}

This study was carried out in a mould maker located at Marinha Grande using a direct observation on the shop floor to see in firsthand the production process.

The data collection was conducted in the field by following one particular mould component that was deemed most important to the mould manufacturing, the core, and time were mesured between and within all stages of it is manufacturing process, from the steel acquisition to the mould try-out. All the data gathered allowed to build one VSM - Value Stream Mapping, where different events were evaluated, namely:

1. Setup (or change-over): Fix the piece, Center the piece, Program, Exchange of die, Move or turn the mould, amongst others tasks;

2. Wait: Machine failure, Wait for the program, Wait for information, Wait for the availability of the crane, Search for tools, Unavailability of the operator, amongst others waits;

3. Others: Transporting piece, Examine, Clean piece, etc.

The different waiting time between steps, in Setup or in turn off have been analyzed, by histogram chart, to verify de reason of this waste. Regarding the 
different stoppage events, a detailed analysis through Pareto diagram was also performed in order to identify the main factors for stoppage.

Parallel to this study, the overall performance of automated equipment's, Machining Centers (CNC), of the company industrial park was analyzed through the Overall Equipment Effectiveness (OEE) assessment. The OEE can establish a working basis for the creation of an improved state of the process with propose of implementation of Lean tools to improve production performance.

In this study has also used a hybrid concept based on continuous improvement of PCDA/DMAIC (Mishra and Sharma, 2014). It is considered that DMAIC is an evolution of PDCA where it started to use statistical tools with analytical power. It is important to reinforce that each step taken, supported by the PDCA/DMAIC cycle, is continuously repeated until perfection is reached. This instrument consists of several activities to achieve a certain improvement, based on the purpose of making processes clearer and more agile (Imai, 1997).

Data processing is done by PDCA/DMAIC cycle (Indrawati and Ridwansyah, 2015). The first stage is identification of production waste during production of moulds parts. In the Measure phase, Pareto diagram is used to determine the critical wastes. Measurement of waste was carried out by qualitative assessment. Then root cause analysis is done to evaluate several factors causing waste. In the improve phase, alternative solution are given to reduce production waste and improve production performance.

The five phases presented in the Fig. 3 follow the DMAIC methodology with the corresponding objectives and the potential tools that can be used.

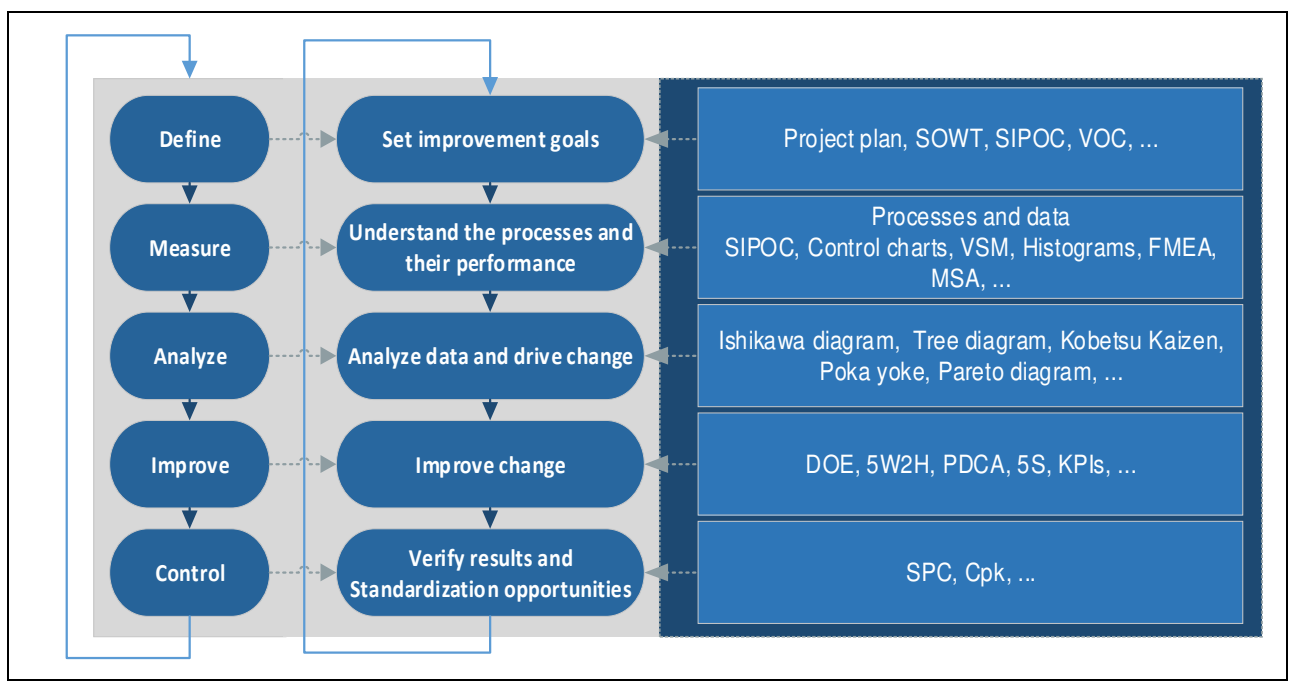

Figure 3 - Improvement Process - Potential Tools 


\section{RESULTS AND DISCUSSION}

The main results are following.

\subsection{Value Stream Mapping (VSM)}

The gathered data, thorough continuous observation of mould's core, allows to building of the VSM type illustrated in Fig. 4. Based on that, it is possible to observe that the lead time is 12 weeks, which corresponds to approximately $164 \mathrm{~h}$ of Cycle time (OCT), 23h related to Change-over (C/O), totaling in average of $60 \%$ availability time. One can also concluded that rework was 29 hours and the total number of hours that the core was remained stopped between the various stages of manufacture was 201 hours.

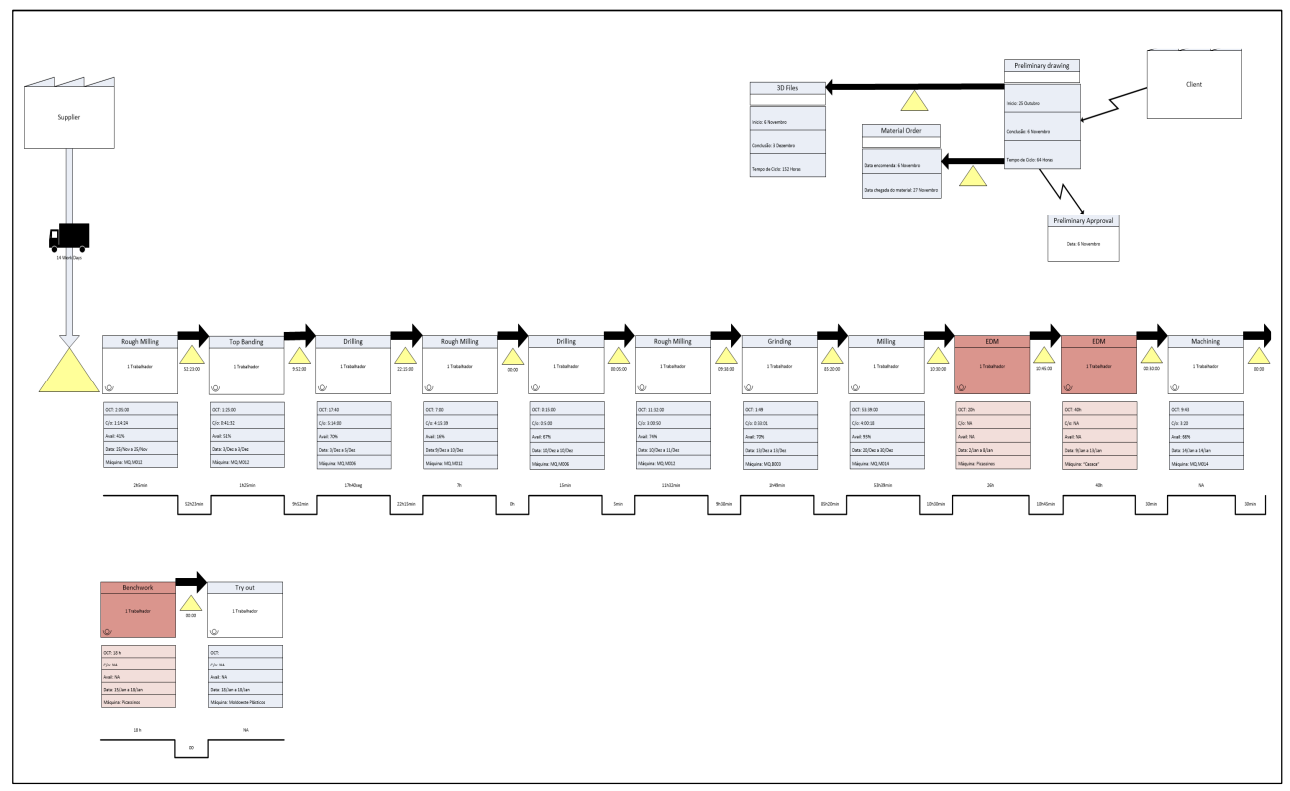

Figure 4-Overview of the VSM Aspect Generated

\subsection{Waste Analysis}

With an analysis of the various types of stoppages, it can be observed that the milling process was the one that exhibits a larger timeout $(40 \%)$, which is expected since it is the most time-consuming stage (see Fig. 5). 


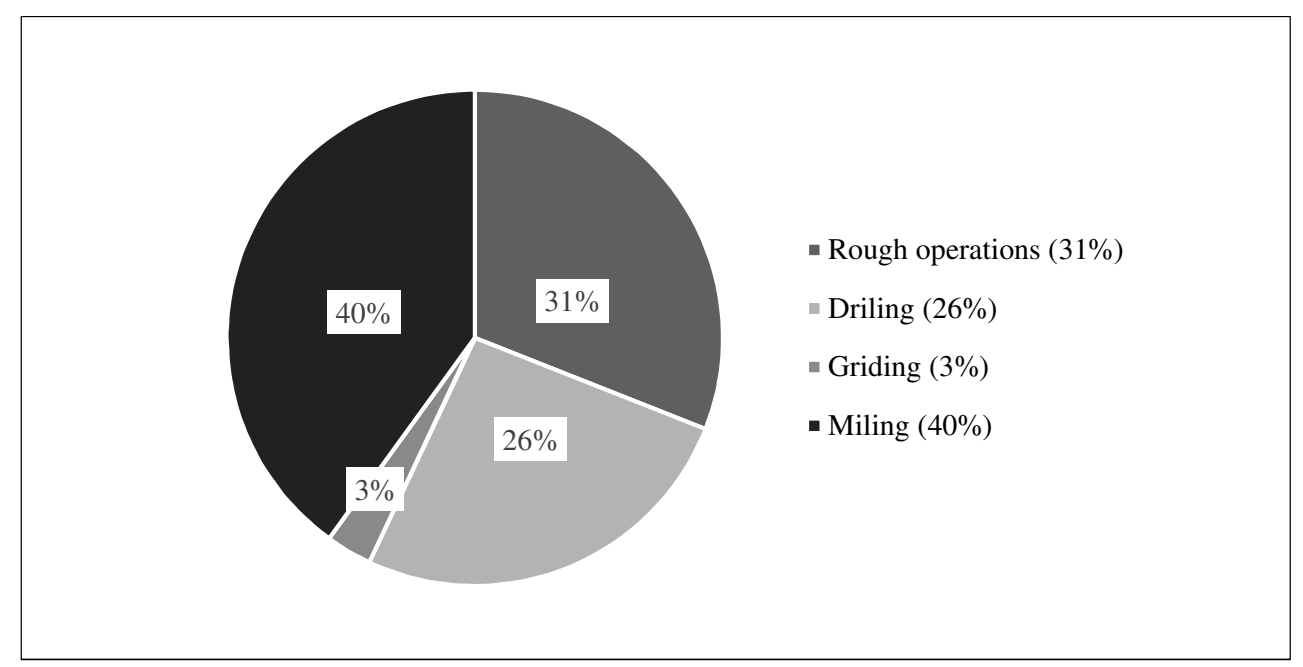

Figure 5 - Stoppages by Sectors

The time values between the various manufacturing stages, is present in Figure 6 in which the core has been stopped without any intervention of any kind. It is important to highlight that for the calculation of the stoppage time, was considered 5 days of manufacturing with a daily load of 20 hours.

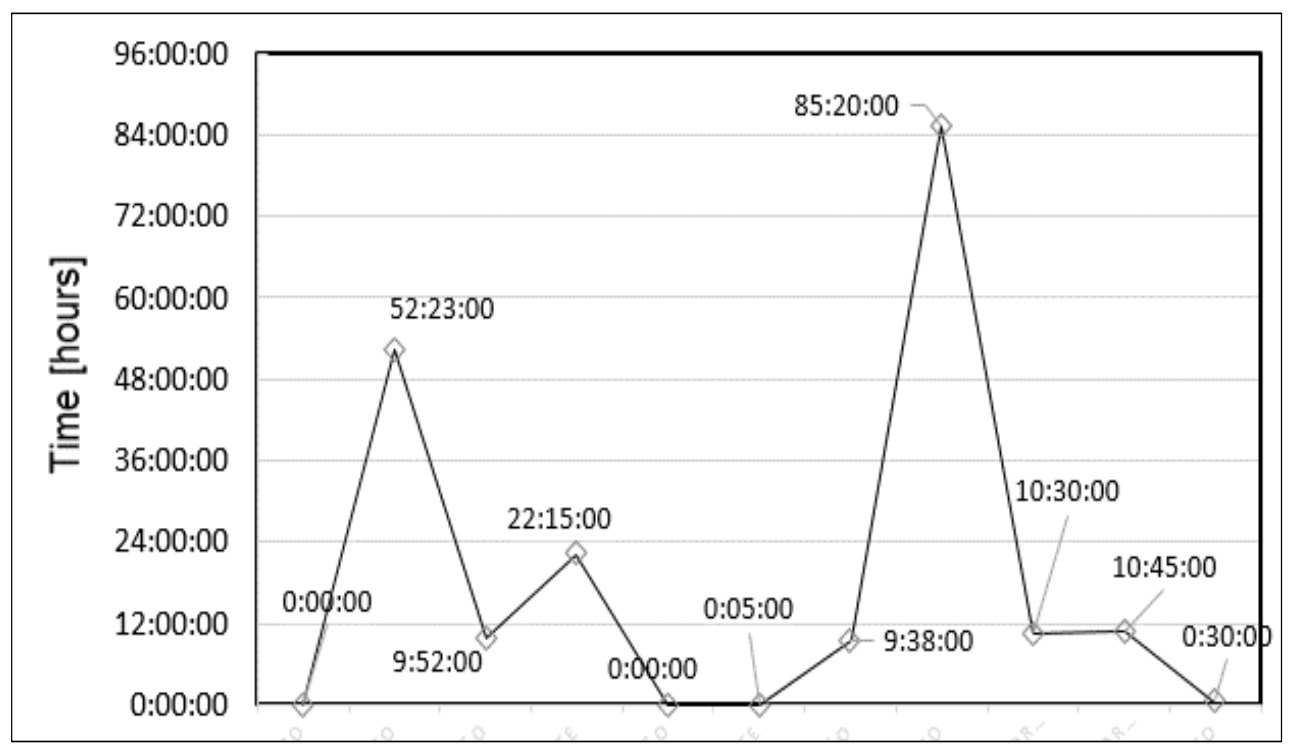

Figure 6 - Waiting Time between Steps

Pareto analysis was carried out to show that events that contributes the most to the stops. The results were: unavailability of the operator $(16.4 \%)$, programming the machine (14.4\%) and tool exchange (12.4\%) (see Fig. 7). 


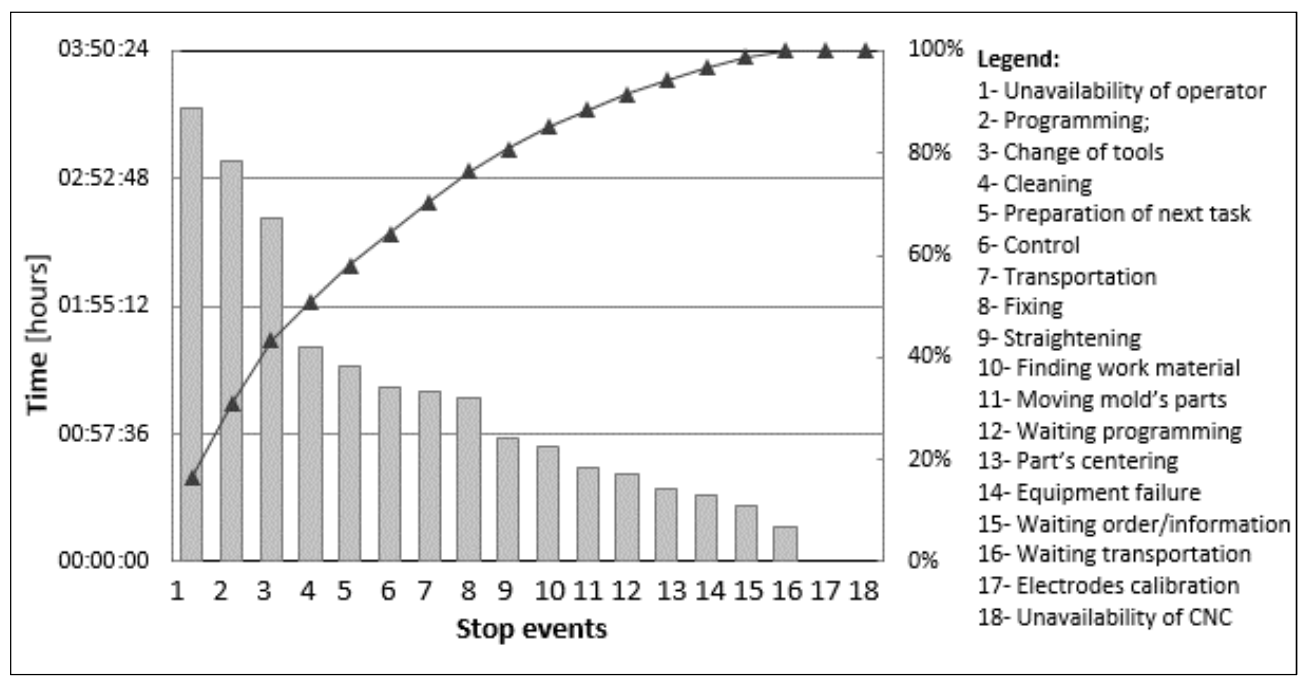

Figure 7 - Contribution of the Different Stoppage Events

Machine states have been recorded. The state of: machine running; machine stop; or machine in Setup were analyzed by histogram to verify the reason for this waste (see Fig. 8).

About the global of analyzed machines it is verified that about $42.9 \%$ of the machines with state "running" is below the machines with "average state of machine running" (46.9\%). With the same tendency, machine state setup average is $14.5 \%$, and have been recorded $47.6 \%$ of the machines with state "machine in setup" above this value. That suggest unbalance production.

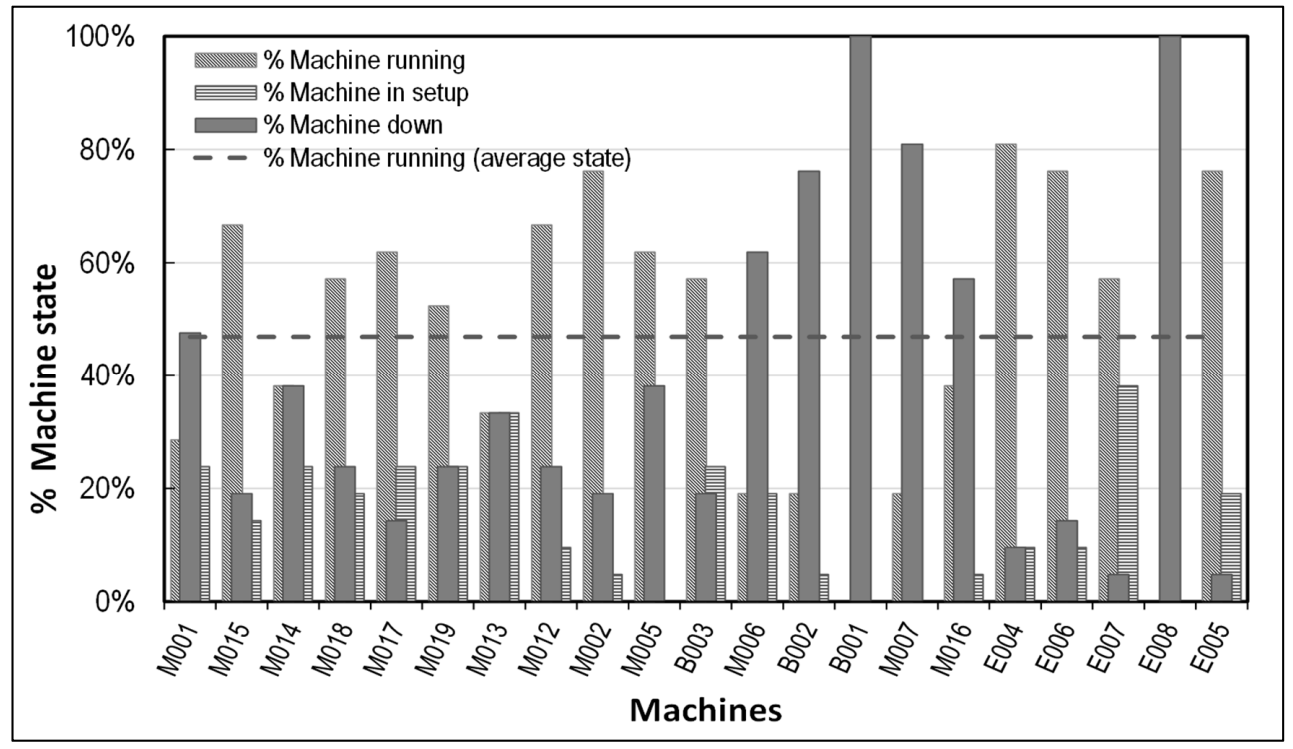

Figure 8-Machine States 
One of the problems detected is related to incorrect task planning. Therefore, the work planning method should be analysed in order to reduce waiting times, operating time, setup time and for this can improve the planning tasks with an enterprise resource planning (ERP) system.

SMED methodology can be implemented to reduce the setup time. With this implementation it is intended to improve some factors, namely: reduction lead time and increased capacity; increase of quality and less process variability; increased flexibility to meet client demands; and better utilization of your workforce and lower manufacturing cost.

\subsection{Overall Equipment Effectiveness (OEE)}

The assessment of OEE was performed for machining centers during a 9 hour shift for six equipment's. Regarding OEE calculation, the following factors were considered:

- Availability: $\quad$ Production Time versus Programmed Time;

- Performance: Real Production versus Ideal Production;

- Quality: Total Conforming Parts versus Total Produced Parts.

Thus, the results obtained for the automated equipments' Machining Centers (CNC), is show in the Tab. 1, where it can be observed that the availability factor is the main problem.

Table 1 - OEE of CNC Machines - Above and Before

\begin{tabular}{|c|c|c|c|c|}
\hline CNC machines & Availability & Effectiveness & Quality rate & OEE \\
\hline Above improvement continuos program \\
\hline 1 & $26 \%$ & $89 \%$ & $87 \%$ & $20.1 \%$ \\
\hline 2 & $38 \%$ & $100 \%$ & $98 \%$ & $37.2 \%$ \\
\hline 3 & $97 \%$ & $97 \%$ & $100 \%$ & $94.1 \%$ \\
\hline 4 & $40 \%$ & $85 \%$ & $92 \%$ & $31.3 \%$ \\
\hline 5 & $73 \%$ & $95 \%$ & $100 \%$ & $69.4 \%$ \\
\hline 6 & $50 \%$ & $88 \%$ & $100 \%$ & $44.0 \%$ \\
\hline Before improvement continuos program & $48 \%$ & $93 \%$ & $89 \%$ & $39.7 \%$ \\
\hline 1 & $68 \%$ & $100 \%$ & $98 \%$ & $66.6 \%$ \\
\hline 2 & $98 \%$ & $97 \%$ & $100 \%$ & $95.1 \%$ \\
\hline 3 & $62 \%$ & $95 \%$ & $97 \%$ & $57.1 \%$ \\
\hline 4 & $88 \%$ & $98 \%$ & $100 \%$ & $86.2 \%$ \\
\hline 5 & $80 \%$ & $96 \%$ & $100 \%$ & $76.8 \%$ \\
\hline 6 & & &
\end{tabular}


The key performance indicators OEE was calculated on CNC Machines at the beginning of the study and a global OEE of CNC Machines about $50 \%$ was obtained. This was followed by the implementation of a (basic) continuous improvement program using Lean Six Sigma tools such as: 5S methodology, SMED methodology; Visual Management and Standard Work. Before a preimplementation, the OEE was recalculated. An improvement of each machine's OEE was achieved and the Global OEE improved by about $20 \%$.

\section{CONCLUSIONS}

The results attained highlight the great potential of the proposed framework to achieve mould production improvements, with consequent time earnings for the entire mould fabrication process, since it illustrates where the problems are (such as higher change overs and waiting time).

Notwithstanding, the data sample collected is very small, and it is therefore appropriate to complement this study, so that one can extrapolate the results obtained in order to sustain improvement actions to reduce, for instance, waiting time.

At the same time, and since the unavailability of resources is identified as the most important cause of waiting time, one considers especially important to create a planning support tools that mitigate all the waiting factors.

Implementation of lean manufacturing tools and practices in the mould industry can bring many benefits, such as reducing waste and creating the value-added products to customers.

This paper provides positive evidence regarding the effects that Lean tools and techniques have on the performance of organizations. This research offers to the mould industries, a better understanding of the relationship between the Lean strategy/management and the performance of their operations.

\section{ACKNOWLEDGEMENTS}

The authors would like to express the special thanks to CDRSP - Centre for Rapid and Sustainable Product Development to produce test samples. This work has been funded by FCT - Portuguese Foundation for Science and Technology (FCT) through the project UID/Multi/04044/2019. 


\section{REFERENCES}

Alaskari, O., Ahmad, M.M., Dhafr, N. and Pinedo-Cuenca, R., 2012. Critical successful factors (CSFs) for successful implementation of lean tools and ERP systems. In: S.I. Ao, L. Gelman, D.W.L. Hukins, A. Hunter and A.M. Korsunsky, Proceedings of the World Congress on Engineering 2012. London, UK, 4-6 July 2012. Hong Kong: Newswood Limited.

Araujo, R., Santos, G., Da Costa, J.B. and Sá, J.C., 2019. The Quality Management System as a Driver of Organizational Culture: An Empirical Study in the Portuguese Textile Industry. Quality Innovation Prosperity Journal, [ejournal] 23(1), pp.1-24. 10.12776/qip.v23i1.1132.

Ayatollahi, I., Hackhofer, M., Kittl, B. and Pauker, F., 2013. New Approach for OEE Calculation of CNC Machines Based on Opc Ua. In: B. Katalinic and Z. Tekic, eds. 2013. DAAAM International Scientific Book. Vienna, Austria: DAAAM International. Chapter 55.

Belekoukias, I., Garza-Reyes, J.A. and Kumar, V., 2014. The impact of lean methods and tools on the operational performance of manufacturing organisations. International Journal of Production Research, [e-journal] 52(18), pp.5346-5366. 10.1080/00207543.2014.903348.

Costa, A., Henriques E., Peças, P. and Domingues, M., 2012. Mapping the mould production process: a work tool for improvement. In: Institute of Polymer Mechanics, Conference Proceedings of PMI Conference 2012. Ghent, Belgium, 13-14 September 2012. Riga, Latvia: The Institute of Polymer Mechanics (IPM). pp. 315-323.

Defeo, J.A. and Juran, J.M., 2016. Juran's Quality Handbook: The Complete Guide to Performance Excellence. 7th edition. New York, USA: McGraw-Hill.

Dutta, S. and Dutta, A.K., 2016. A Review on the experimental study of Overall Equipment Effectiveness of various machines and its improvement strategies through TPM implementation. International Journal of Engineering Trends and Technology (IJETT), 36(5), pp.224-232.

Figueiredo, M.S.N and Pereira, A.M., 2017. Managing knowledge - the importance of databases in the scientific Production. International Conference on Sustainable and Intelligent Manufacturing. Procedia Manufacturing, 12, pp.166173.

Garza-Reyes, J.A., Oraifige, I., Soriano-Meier, H., Forrester, P.L. and Harmanto, D., 2012. The development of a lean park homes production process using process flow and simulation methods. Journal of Manufacturing Technology Management, [e-journal] 23(2), pp.178-197. 10.1108/17410381211202188.

Ghodrati, A. and Zulkifli, N., 2013. The Impact of 5S Implementation on Industrial Organizations' Performance. International Journal of Business and Management Invention, 2(3), pp.43-49. 
Glover, W.J., Farris, J.A., Van Aken, E.M.V. and Doolen, T.L., 2011. Critical Success Factors for the Sustainability of Kaizen Event Human Resource Outcomes: An Empirical Study. International Journal of Production Economics, [e-journal] 132(2), pp.197-213. 10.1016/j.ijpe.2011.04.005.

Henriques, E. and Peças, P., 2012. New Business Models for the Tooling Industry. In: W.D. Nelson, ed. 2012. Advances in Business and Management. New York: Nova Science Publishers. Vol. 4.

Hines, P. and Rich, N., 1997. The seven value stream mapping tools. International Journal of Operations \& Production Management, [e-journal] 17(1), pp.46-64. 10.1108/01443579710157989.

Imai, M., 1997. Gemba Kaizen: A Commonsense, Low-Cost Approach to Management. New York, USA: McGraw-Hill.

Indrawati, S. and Ridwansyah, M., 2015. Manufacturing Continuous Improvement Using Lean Six Sigma: An Iron Ores Industry Case Application. Procedia Manufacturing, 4, pp.528-534. 10.1016/j.promfg.2015.11.072.

International Special Tooling \& Machining Association (ISTMA World), 2007. ISTMA Statistical Year Book: on tools, dies and moulds industry international trade and manufacturing. Marinha Grande, Portugal: ISTMA.

Ishikawa, K., 1986. Guide to Quality Control. Tokyo, Japan: Asian Productivity Organization.

Ishikawa, K., 1991. What Is Total Quality Control?: The Japanese Way. Upper Saddle River, New Jersey: Prentice Hall Direct.

Jonsson, P. and Lesshammar, M., 1999. Evaluation and improvement of manufacturing performance measurement systems - the role of OEE. International Journal of Operations \& Production Management, [e-journal] 19(1), pp.55-78. ht10.1108/01443579910244223.

Jorge, D.P. and Peças, P., 2018. Mapeamento do progresso de moldes - uma ferramenta de gestão visual para a indústria 4.0. Revista Produção $e$ Desenvolvimento, 4(1), pp.68-81.

Liker, J.K., 2004. The Toyota Way: 14 Management Principles from the World's Greatest Manufacturer. New York, USA: McGraw-Hill.

Liker, J.K. and Meier, D., 2006. The Toyota Way Fieldbook. New York, USA: McGraw-Hill.

Magar, V.M. and Shinde, V.B., 2014. Application of 7 Quality Control Tools for Continuous Improvement of Manufacturing Processes. International Journal of Engineering Research and General Science, 2(4), pp.364-371.

Manzouri, M., Ab-Rahman, M.N., Zain, C.R. and Jamsari, E.A., 2014. Increasing production and eliminating waste through lean tools and techniques for halal food companies. Sustainability, [e-journal] 6, pp.9179-9204. 10.3390/su6129179. 
Marodin, G.A. and Saurin, T.A., 2013. Implementing lean production systems: research areas and opportunities for future studies. International Journal of Production Research, 51(22), pp.6663-6680. 10.1080/00207543.2013.826831.

Mishra, P. and Sharma, R.K., 2014. A hybrid framework based on SIPOC and Six Sigma DMAIC for improving process dimensions in supply chain network. International Journal of Quality \& Reliability Management, [e-journal] 31(5), pp.522-546. 10.1108/IJQRM-06-2012-0089.

Ohno, T., 1988. Toyota Production System: Beyond Large-Scale Production. Abingdon, United Kingdom: Taylor \& Trancis Group.

Oliveira, J., Sá, J.C. and Fernandes, A., 2017. Continuous Improvement Through "Lean Tools" - Application in a mechanical company. Procedia Manufacturing, [e-journal] 13, pp.1082-1089. 10.1016/j.promfg.2017.09.139.

Prakash, D. and Sunil Kumar, C.T., 2011. Implementation of Lean Manufacturing Principles in Auto Industry. Industrial Engineering Letters, 1(1), pp.56-60.

Puvanasvaran, P., Teoh, Y.S. and Tay, C.C., 2013. Consideration of demand rate in Overall Equipment Effectiveness (OEE) on equipment with constant process time. Journal of Industrial Engineering and Management, [e-journal] 6(2), pp.507-524. 10.3926/jiem.537.

Rother, M., 2010. Toyota Kata: Managing People for Improvement, Addictiveness and Superior Results. New York, USA: McGraw-Hill.

Rother, M. and Shook, J., 2003. Learning to see: value stream mapping to add value and eliminate muda. Brookline, USA: Lean Enterprise Institute.

Santos, G., Gomes, S., Braga, V., Braga, A., Lima, V., Teixeira, P. and Sá, J., 2019. Value creation through quality and innovation - a case study on Portugal. The TQM Journal, [e-journal] 31(6), pp.928-947. 10.1108/TQM-12-2018-0223.

Sohal, A. and Egglestone, A., 1994. Lean production: experience among Australian organizations. International Journal of Operations and Production Management, [e-journal] 14(11), pp. 35-51. 10.1108/01443579410068639.

Tajiri, M. and Gotoh, F., 1992. TPM Implementation: A Japanese Approach. New York, USA: McGraw-Hill.

Thangarajoo, Y. and Smith, A., 2015. Lean Thinking: An Overview. Industrial Engineering \& Management, [e-journal] 4(2), pp.1000159. 10.4172/21690316.1000159 .

Womack, J.P. and Jones, D.T., 1996. Lean thinking: Banish waste and create wealth in your corporation. New York, USA: Simon and Schuster.

Womack, J.P. and Jones, D.T., 2003. Lean thinking: banish waste and create wealth in your corporation. New York, USA: Free Press. 
Womack, J.P., Jones, D.T. and Roos, D., 1990. Machine that changed the world. New York, USA: Simon and Schuster Inc.

Wongwiwat, A., Bohez, E.L.J. and Pisuchpen, R., 2013. Production scheduling for injection molding manufacture using Petri Net model. Assembly Automation, [e-journal] 33(3), pp.282-293. 10.1108/AA-12-2013-063.

World Economic Forum (WEF), 2016. The New Plastics Economy: Rethinking the future of plastics. [pdf] Cologny/Geneva, Switzerland: WEF. Available at: $<$ http://www3.weforum.org/docs/WEF_The_New_Plastics_Economy.pdf $>$ [Accessed 27 November 2019].

\section{ABOUT AUTHORS}

António M.H. Pereira - has a $\mathrm{PhD}$ degree in Sciences of Mechanical Engineering from the University of Coimbra. Mário Pereira is Associate Professor at the Polytechnic Institute of Leiria (IPL) and Member of the Centre for Rapid and Sustainable Product Development (CDRsp) at the same Institute. Member of the organizing committees and Member of the scientific committees of the several International Conference. Mario Pereira is a reviewer of several International journal and Conferences. He worked in the industry for several years as a Quality Management Systems and Laboratory test. He is/was supervisor/co-supervisor of MSc and Ph.D Students. He has co-edited several of books, authored and co-authored of papers published in books, international journals and international conferences. His research interests are Mechanical Design; Fatigue of Materials; Metamaterials, mainly Mechanical behaviour of materials, Mechanical Design; Fatigue of Materials; CFRP and GFRP with long and short fibers; Additive Manufacture; Direct digital manufacturing/4D Printing; Multifunctional Materials/Smart Materials/Metamaterials; Total quality management/LEAN and SIX SIGMA. E-mail: mario.pereira@ipleiria.pt, Author's ORCID: 0000-0003-1219-0596.

Miguel R. Silva - has a Master degree in Mechanical Engineering from Polytecnic Institute of Leiria and is a PhD degree student in Sciences of Polimer Engineering from the University of Minho. Miguel R. Silva is Professor at the Polytechnic Institute of Leiria (IPL) and Member of the Centre for Rapid and Sustainable Product Development (CDRsp) at the same Institute. He has authored and co-authored of papers published in books, international journals and international conferences. His research interests are Mechanical Design; Metamaterials, mainly Mechanical behaviour of materials, Mechanical Design; Fatigue of Materials; CFRP and GFRP with long and short fibers; Additive Manufacture; Direct digital manufacturing/4D Printing; Multifunctional Materials/Smart Materials/Metamaterials. E-mail: miguel.r.silva@ipleiria.pt, Author's ORCID: 0000-0001-6133-3229. 
Mercedes A.G. Domingues - has a first degree of Mechanical Engineering from the University of Coimbra. Mercedes Domingues is invated Professor at the Polytechnic Institute of Leiria (IPL) and Member of the CENTIMFE. Member of the organizing committees and Member of the scientific committees of the several. E-mail: mercedes.domingues@ipleiria.pt, Author's ORCID: 0000-00022731-8911.

José C. Sá - is graduated in Production Engineering from the Minho University (1998). He holds a Master's Degree in Industrial Engineering - option: Quality, Safety and Maintenance, by the Minho University (2010). In 2015 he is awarded the title of Specialist in Quality Management, by the Polytechnic Institute of Viana do Castelo. He is currently a PhD student in Industrial and Systems Engineering. José Carlos is a professor at the Engineering School of Porto, at the Polytechnic of Porto, and also at Polytechnic Institute of Viana do Castelo. Consultant (since 2004) in several companies, in safety, quality and industrial engineering. In 2015, José Carlos became a "senior member" of the Portuguese Engineer Association. He has published several articles and chapter books on quality management, safety and lean. E-mail: cvs@isep.ipp.pt, Author's ORCID: 0000-0002-2228-5348.

Conflicts of Interest: The authors declare no conflict of interest.

(C) 2019 by the authors. Submitted for possible open access publication under the terms and conditions of the Creative Commons Attribution (CC-BY) license (http://creativecommons.org/licenses/by/4.0/). 